\title{
Particulate Sintering of Iron Ore and Empirical Analysis of Sintering Time Based on Coke Breeze Input and Ignition Temperature
}

\author{
C. I. Nwoye ${ }^{1}$, E. E. Nnuka ${ }^{1}$, V. O. Nwokocha ${ }^{1,2}$ and S. O. Nwakpa ${ }^{1}$ \\ ${ }^{I}$ Department of Materials and Metallurgical Engineering, Nnamdi Azikiwe University Awka, Nigeria \\ ${ }^{2}$ Federal Ministry of Works, Abuja
}

\begin{abstract}
Particulate sintering of iron ore has been carried out using the necessary ingredients. Empirical analysis of the sintering time based on the coke breeze input concentration and ignition temperature were also successfully obtained through first principle application of a derived model which functioned as a evaluative tool. The derived model;

$$
S=(\sqrt{ } T)^{0.95}+0.0012 \alpha
$$

indicates that amongst ignition temperature and coke breeze input, sintering time is more significantly affected by the coke breeze input concentration. This is based on the higher correlation it makes with sintering time compared to applied ignition temperature, all other process parameters being constant. The validity of the model was rooted in the core expression $S-K \alpha \approx(\sqrt{ } T)^{N}$ where both sides of the expression are correspondingly approximately almost equal. Sintering time per unit rise in the operated ignition temperature as obtained from experiment, derived model and regression model were evaluated as $0.0169,0.0128$ and 0.0159 mins. $/{ }^{0} \mathrm{C}$ respectively. Similarly, sintering time per unit coke breeze input concentration as obtained from experiment, derived model and regression model were evaluated as 4.0, 3.0183 and 3.7537 mins./\% respectively indicating a significant proximate agreement and validity of the model. The standard error (STEYX) incurred in predicting sintering time for each value of the ignition temperature and coke breeze input concentration considered, as obtained from the experiment, derived model and regression model are 1.6646, 0.7678 and $2.98 \times 10^{-5} \%$ as well as $2.2128,1.0264$ and $1.2379 \%$ respectively. The maximum deviation of mode-predicted results from the corresponding experimental values was less than $11 \%$.
\end{abstract}

Keywords: Particulate Iron Ore Sintering, Sintering Time, Ignition Temperature, Coke Breeze Input.

\section{Introduction}

Sinter characteristics are basically a principal factor on which the blast furnace performance significantly depends [1]. It is widely accepted that sintering increases the particle size, to form a strong reducible agglomerate, to remove volatiles and sulphur, and to incorporate flux into the blast-furnace burden.

Report [2] has shown that in sintering, a shallow bed of fine particles is agglomerated by heat exchange and partial fusion of the quiescent mass. Heat is generated by combustion of a solid fuel admixed with the bed of iron bearing fines being agglomerated. The combustion is initiated by igniting the fuel exposed at the surface of the bed, after which a narrow, high temperature zone is caused to move through the bed by an induced draft, usually applied at the bottom of the bed. Within this narrow zone, the surfaces of adjacent particles reach fusion temperature, and gangue constituents form a semi-liquid slag. The bonding is affected by a combination of fusion, grain growth and slag liquidation. The generation of volatiles from the fuel and fluxstone creates a frothy condition and the incoming air quenches and solidifies the rear edge of the advancing fusion zone. The product consists of a cellular mass of ore bonded in a slag matrix.

One of the most important thermal operations in integrated iron and steel plant is sintering of raw iron ore, mostly haematite $\left(\mathrm{Fe}_{2} \mathrm{O}_{3}\right)$. In the sintering process, a mixture of iron ores, coke, lime or limestone, and iron bearing residue (e.g blast flue dust, mill scale, scrap and other waste material recycled from within or outside the steel plant.) is heated at high temperatures and sintered into a porous, calibrated feedstock acceptable to the blast furnace. Almost all types of ferro waste available in iron and steel works can be utilized in appropriate proportions to produce quality sinters [3].

Studies [3] have shown that approximately $6.7 \%$ of the total energy consumed in iron and steel production is required for sinter production. Development and growth in the iron and steel industries all over the world has militated against the availability of prime coking coal with adequate properties to yield metallurgical coke. This situation has increasingly becoming more severe, making procurement of such coke expensive [3].

A several researches in the sintering area include energy consumption and productivity process control. Significant reduction in energy have already been achieved in sintering plant as a result of utilization of improved raw materials characteristics of ores and coke breeze in terms of size and composition [3]. This 
invariably results to reduction in sintering time since association reactions are increasingly vigorous. Coke breeze-less sintering has been found [3] advantageous for profitable investment because usage sintering machine is more economical than rotary kiln or other reduction facilities. Coke breeze is has been found [2] the most common solid fuel, but other carbonaceous materials can be used. When sintering a high sulphur material, such as a pyrite, the oxidation of the sulfur may satisfy completely the fuel requirements. It has also become common practice to incorporate limestone fines into the sinter mix, and this material may now be considered as a usual constituent in a typical sinter mix. This composite of fine material is well mixed and placed on the sinter strand in a shallow bed, seldom less than 6 inches or more than 20 inches in depth. Upon ignition, within a furnace which straddles the bed, the surface of the bed is heated to about $2300^{\circ}$ to $2500{ }^{\circ} \mathrm{F}$, combustion of the fuel is initiated, and the fine particles at the surface are fused together. As air is drawn through the bed, the high temperature zone of combustion and fusion moves downwardly through the bed and produces a bonded, cellular structure.

It has been established [4] during a sintering process, that part of the solid fuel can be replaced by treating the charge with hot gases following ignition. Returned process gases from the sintering operation or other suitable gases are mixed with oxygen and are applied to the charge from a burner hood which overhangs part of the sintering strand. The length of the hood generally in use is about one-third of the length of the sintering strand, and the gas temperature, depending on the sinter mixture used, is between $700^{\circ} \mathrm{C}$. and $1200^{\circ} \mathrm{C}$. Previous efforts to ensure uniformity of the sinter by finding an optimum combination of hood length and gas temperature, while at the same time maintaining the thermal efficiency of the operation, have been generally unsuccessful. Reduced hood length was not desirable since the coke fine content had to be increased substantially. The report shows that a noticeable decrease in efficiency occurred with a longer hood. The researchers stated that selection of too high a gas temperature entailed the danger of excessive slagging of the charge surface.

The aim of this work is sintering of iron ore and empirically analyzing sintering time based on coke breeze input concentration and ignition temperature.

\subsection{Sinter Production}

\section{Materials and Methods}

Sinters were produced from iron ore and other ingredients such as limestone, coke etc considering a range of ignition temperature $\left(864-1100^{\circ} \mathrm{C}\right)$ and operation time range of $27-31$ mins and coke breeze input: 5$6.2 \%$, in order to evaluate the sintering time. Details of the experimental procedures and equipment used are as stated in the report [5].

\subsection{Model Formulation}

Results from the experimental work [5]were used for the model derivation. These results are as presented in Table 1 and their computational analysis using C-NIKBRAN [6] resulted to Table 2 which indicate that;

$$
\mathrm{S}-\mathrm{K} \alpha \approx(\sqrt{ } \mathrm{T})^{\mathrm{N}}
$$

Adding $\mathrm{K} \alpha$ to both sides of equation (1) reduces it to:

$$
\mathrm{S}=(\sqrt{T})^{\mathrm{N}}+\mathrm{K} \alpha
$$

Introducing the values of $\mathrm{K}$ and $\mathrm{N}$ to (equation (2) gives:

$$
S=(\sqrt{ } T)^{0.95}+0.0012 \alpha
$$

Where

$\mathrm{S}=$ Sintering time (mins.)

$\mathrm{T}=$ Ignition temperature $\left({ }^{0} \mathrm{C}\right)$

$\mathrm{K}=0.0012$ : Ore - coke breeze interaction factor (determined using C-NIKBRAN, [6])

$\mathrm{N}=$ 0.95: Coefficient of reaction resistance due to Ore-temperature interaction (determined using C-

NIKBRAN, [6])

$(\alpha)=$ Concentration of coke breeze $(\%)$

Equation (3) is the derived model.

Table 1: Variation of the sintering time with ignition temperature [5] 


\begin{tabular}{|c|c|c|}
\hline Sintering time (mins.) & $\mathrm{C} \%$ & $\mathrm{~T}\left({ }^{0} \mathrm{C}\right)$ \\
\hline 27 & 5.0 & 864 \\
26 & 5.5 & 897 \\
29 & 5.7 & 917 \\
25 & 6.2 & 963 \\
28 & 5.0 & 987 \\
29 & 6.0 & 1053 \\
31 & 6.0 & 1100 \\
& & \\
& & \\
\hline
\end{tabular}

\section{Boundary and Initial Conditions}

In a sintering machine with height of sintering layer; $200 \mathrm{~mm}$, sinter mix was place prior to application of heat and pressure. The percent of coke breeze added; 5-6.2\%, and the operation temperature range 864$1100^{\circ} \mathrm{C}$. Operation time range; $27-31$ mins. Range of pressure used; 6Kpa-1.2 Mpa.

The boundary conditions considered for the sinter production includes: assumption of a zero gradient for the gas phase at the top of particles. It was assumed that atmospheric oxygen interacted with the flowing gases, produced at the top and bottom of the mix. The sides of the mix particles were assumed to be symmetries.

\section{Results and Discussions}

The derived model is equation (3). Computational analysis of experimental results presented in Table 1 gave rise to Table 2 .

Table 2: Variation of $\mathrm{S}-0.0012 \alpha$ with $(\sqrt{ } \mathrm{T})^{0.95}$
\begin{tabular}{|c|c|}
\hline $\mathrm{S}-0.0012 \alpha$ & $(\sqrt{\mathrm{T}})^{0.95}$ \\
\hline 26.9940 & 24.8224 \\
25.9934 & 25.2683 \\
28.9932 & 25.5344 \\
24.9926 & 26.1350 \\
27.9940 & 26.4424 \\
28.9928 & 27.2680 \\
30.9928 & 27.8395 \\
\hline
\end{tabular}

The derived model indicates that amongst ignition temperature and coke breeze input, sintering time is more significantly affected by the coke breeze input concentration. This is based on the higher correlation it makes with sintering time compared to applied ignition temperature, all other process parameters being constant.

\subsection{Model validation}

The validity of the model is strongly rooted on equation (1) (core model equation) where both sides of the equation (on introducing the values of $\mathrm{K}, \alpha, \mathrm{T}$ and $\mathrm{N}$ into equation (1)) are correspondingly approximately equal. Table 2 also agrees with equation (1) following the values of $S-K \alpha$ and $(\sqrt{ } T)^{N}$ evaluated from the experimental results in Table 1. Furthermore, the derived model was validated by comparing the sintering times predicted by the model and that obtained from the experiment. This was done using various analytical techniques which include: computational, statistical, graphical and deviational analysis.

\subsubsection{Computational Analysis}

Sintering time per unit rise in ignition temperature

The sintering times per unit rise in ignition temperature obtained by calculations involving experimental results and model-predicted results were compared to ascertain the degree of validity of the model.

Sintering time per unit rise in the ignition temperature $\mathrm{S}_{\mathrm{t}}$, $\left(\operatorname{mins} /{ }^{0} \mathrm{C}\right)$ was calculated from the equation;

$$
\mathrm{S}_{\mathrm{tT}}=\mathrm{S}_{\mathrm{t}} / \mathrm{T}
$$

Therefore, a plot of sintering time against ignition temperature, as in Fig. 1 using experimental results in Table 1, gives a slope, $S$ at points $(27,864)$ and $(31,1100)$ following their substitution into the mathematical expression

$$
\mathrm{S}_{\mathrm{tT}}=\Delta \mathrm{S}_{\mathrm{t}} / \Delta \mathrm{T}
$$

Equation (5) is detailed as

Where

$$
\mathrm{S}_{\mathrm{tT}}=\mathrm{S}_{\mathrm{t} 2}-\mathrm{S}_{\mathrm{t} 1} / \mathrm{T}_{2}-\mathrm{T}_{1}
$$


$\Delta \mathrm{S}_{\mathrm{t}}=$ Change in the sintering times $\mathrm{S}_{\mathrm{L}}, \mathrm{St}_{1}$ at two temperature values $\mathrm{T}_{2}, \mathrm{~T}_{1}$. Considering the points $(27,864)$ and $(31,1100)$ for $\left(S_{t 1}, T_{1}\right)$ and $\left(S_{t 2}, T_{2}\right)$ respectively, and substituting them into equation (6), gives the slope as 0.0169 mins. $/^{0} \mathrm{C}$ which is the sintering time per unit rise in the ignition temperature during the actual experimental process.

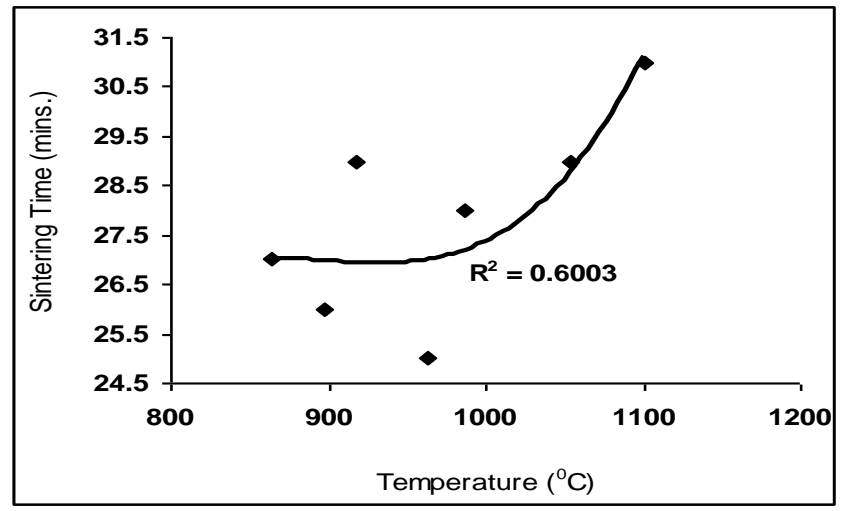

Fig. 1: Coefficient of determination between sintering time and ignition temperature as obtained from experiment

Also similar plot (as in Fig. 2) using model-predicted results gives a slope. Considering points (24.8284, $864)$ and $(27.8467,1100)$ for $\left(\mathrm{S}_{\mathrm{t} 1}, \mathrm{~T}_{1}\right)$ and $\left(\mathrm{S}_{12}, \mathrm{~T}_{2}\right)$ respectively and substituting them into equation (6) gives the value of slope, $\mathrm{S}$ as $0.0128 \mathrm{mins} . /^{\circ} \mathrm{C}$. This is the model-predicted sintering time per unit rise in the ignition temperature. Similarly, a plot (as in Fig. 3) using regression model-predicted results of points $(26.1916,864)$ and $(29.9453$, $1100)$ for $\left(\mathrm{S}_{\mathrm{t} 1}, \mathrm{~T}_{1}\right)$ and $\left(\mathrm{S}_{12}, \mathrm{~T}_{2}\right)$ respectively and substituting them into equation (6) gives the slope, $\mathrm{S}$ as 0.0159 mins. / ${ }^{0} \mathrm{C}$. This is the regression model-predicted sintering time per unit rise in the ignition temperature.

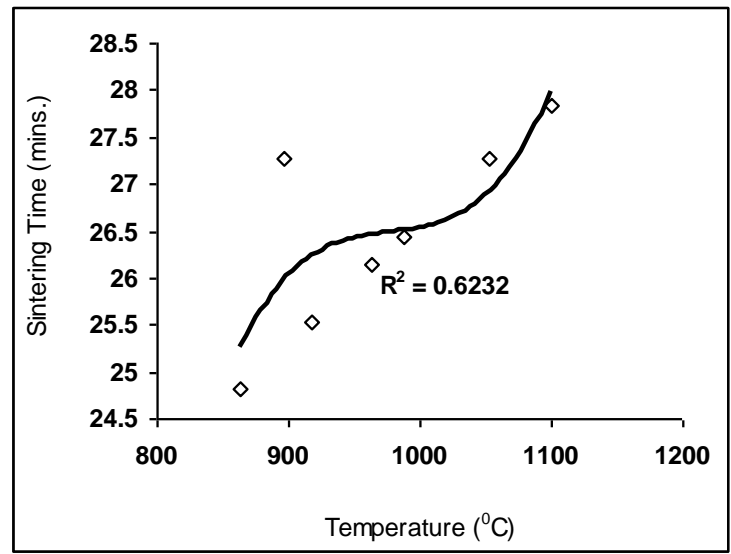

Fig. 2: Coefficient of determination between sintering time and ignition temperature as obtained from derived model

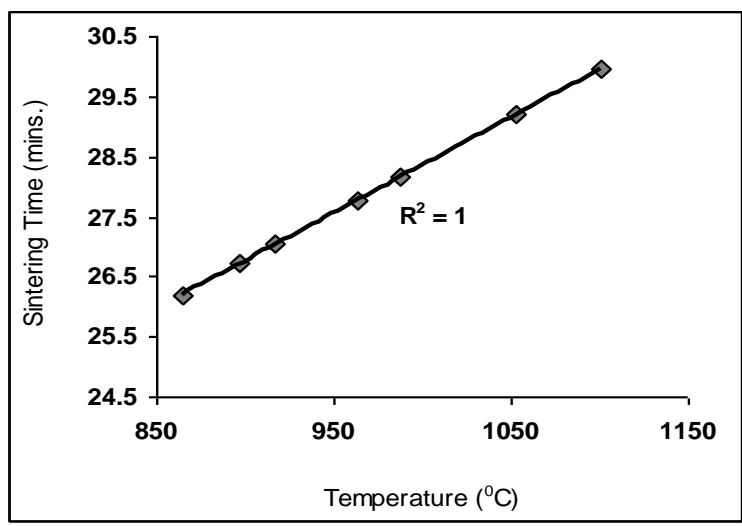

Fig. 3: Coefficient of determination between sintering time and ignition temperature as obtained from regression model 
Sintering time per unit coke breeze input concentration

The sintering times per unit coke breeze input concentration obtained by calculations involving experimental results and model-predicted results were also compared to ascertain the degree of validity of the model.

Sintering time per unit coke breeze input concentration $\mathrm{S}_{\mathrm{C}}$, (mins $\left./ \%\right)$ was calculated from the equation;

$$
\mathrm{S}_{\mathrm{C}}=\mathrm{S}_{\mathrm{t}} / \mathrm{C}
$$

Therefore, a plot of sintering time against coke breeze input concentration, as in Fig. 4 using experimental results in Table 1 , gives a slope, $S$ at points $(27,5)$ and $(31,6)$ following their substitution into the mathematical expression

$$
\mathrm{S}_{\mathrm{C}}=\Delta \mathrm{S}_{\mathrm{t}} / \Delta \mathrm{C}
$$

Equation (8) is detailed as

Where

$$
\mathrm{S}_{\mathrm{C}}=\mathrm{S}_{\mathrm{t} 2}-\mathrm{S}_{\mathrm{t} 1} / \mathrm{C}_{2}-\mathrm{C}_{1}
$$

$\Delta \mathrm{S}_{\mathrm{t}}=$ Change in the sintering times $\mathrm{S}_{2}, \mathrm{St}_{1}$ at two coke breeze input concentrations $\mathrm{C}_{2}, \mathrm{C}_{1}$. Considering the points $(27,5)$ and $(31,6)$ for $\left(S_{t 1}, C_{1}\right)$ and $\left(S_{t 2}, C_{2}\right)$ respectively, and substituting them into equation (9), gives the slope as 4.0 mins. $\%$ which is the sintering time per unit coke breeze input concentration during the actual experimental process. Similarly, considering points $(24.8284,5)$ and $(27.8467,6)$ for $\left(S_{11}, C_{1}\right)$ and $\left(S_{12}, C_{2}\right)$ respectively from model-predicted results (as in Fig. 5) and substituting them into equation (9) gives the slope, $\mathrm{S}$ as 3.0183 mins. $\%$. This is the model-predicted sintering time per unit coke breeze input concentration

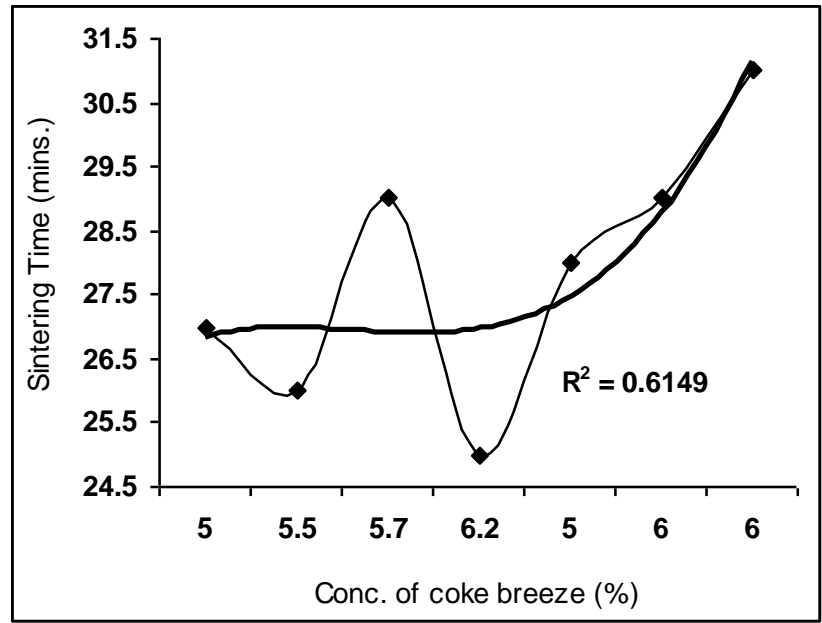

Fig. 4: Coefficient of determination between sintering time and coke breeze input concentration as obtained from experiment

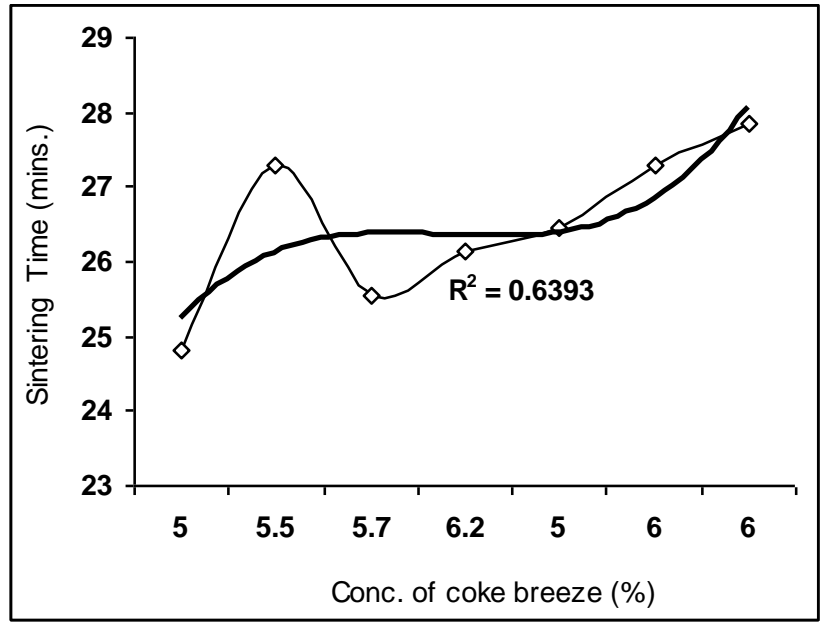

Fig. 5: Coefficient of determination between sintering time and coke breeze input concentration as obtained from derived model

Also, substituting points $(26.1916,5)$ and $(29.9453,6)$ for $\left(S_{t 1}, C_{1}\right)$ and $\left(S_{12}, C_{2}\right)$ respectively from regression model-predicted results (as in Fig. 6) and substituting them into equation (9) gives the slope, $\mathrm{S}$ as 3.7537 mins. $\%$. This is the regression model-predicted sintering time per unit coke breeze input concentration. A critical 
analysis and comparison of these three sets of sintering times; per unit rise in ignition temperature and per unit coke breeze input concentration shows proximate agreement and a significantly high level of derived model validity.

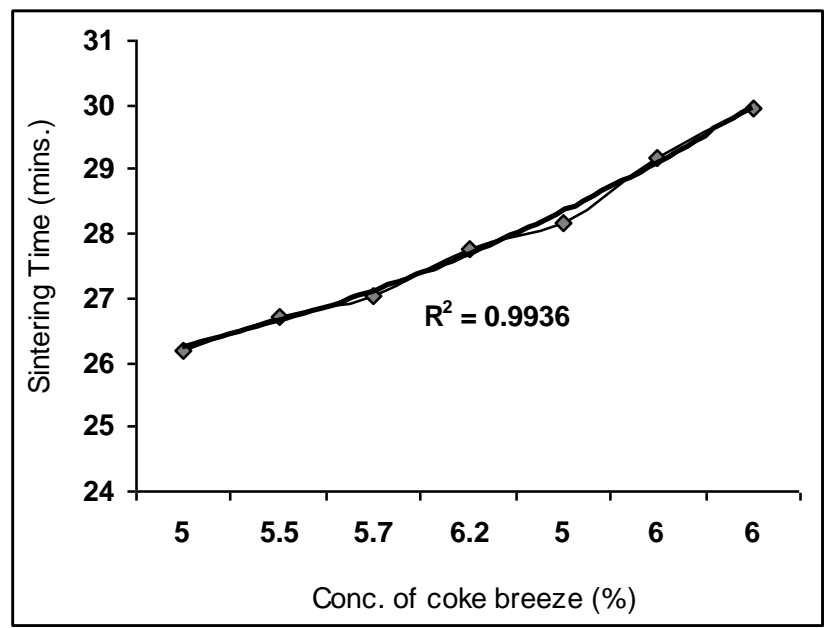

Fig. 6: Coefficient of determination between sintering time and coke breeze input concentration as obtained from regression model

\subsubsection{Statistical analysis}

Statistical analysis of model-predicted, regression-model predicted and experimentally evaluated sintering time for each value of the ignition temperature applied and coke breeze input concentration considered shows a standard error (STEYX) of 0.7678, $2.98 \times 10^{-5} \& 1.6646 \%$ and $1.0264,1.2379 \& 2.2128 \%$ respectively. The standard error was evaluated using [7].

The correlations between sintering time and ignition temperature as well as sintering time and coke breeze input concentration as obtained from derived model, regression model and experimental results were calculated. This was done by considering the coefficients of determination $\mathrm{R}^{2}$ from Figs. 1-6, using the equation;

$$
\mathrm{R}=\sqrt{ } \mathrm{R}^{2}
$$

The evaluated correlations are shown in Tables 4 and 5. The model was also validated by comparing its results of evaluated correlations between sintering time and ignition temperature as well as sintering time and coke breeze input concentration with that evaluated using experimental and regression model-predicted results. Tables 4 and 5 show that the correlation result from experiment, derived model and regression model are in proximate agreement.

Table 4: Comparison of the correlations between sintering time and ignition temperature as evaluated from experimental (ExD), derived model (MoD) and regression-model (LSM) predicted results

\begin{tabular}{|l|c|c|l|}
\hline \multirow{2}{*}{ Analysis } & \multicolumn{3}{|c|}{ Based on ignition temperature } \\
\cline { 2 - 4 } & ExD & MoD & LSM \\
\hline CORREL & 0.7748 & 0.7894 & 1.0000 \\
\hline
\end{tabular}

Table 5: Comparison of the correlations between sintering time and coke breeze input concentration as evaluated from experimental, derived model and regression-model predicted results

\begin{tabular}{|l|c|c|c|}
\hline \multirow{2}{*}{ Analysis } & \multicolumn{3}{|c|}{ Based on coke breeze input concentration } \\
\cline { 2 - 4 } & ExD & MoD & LSM \\
\hline CORREL & 0.7842 & 0.7996 & 0.9968 \\
\hline
\end{tabular}

\subsubsection{Graphical Analysis}

Comparative graphical analysis of Figs. 7 and 8 shows very close alignment of the curves from derived model and experiment. Figs. 9 and 10 also indicate a close alignment of curves from derived model, regressionmodel predicted results as well as experimental results of sintering time. It is strongly believed that the degree of alignment of these curves is indicative of the proximate agreement between ExD, MoD and LSM predicted results. 


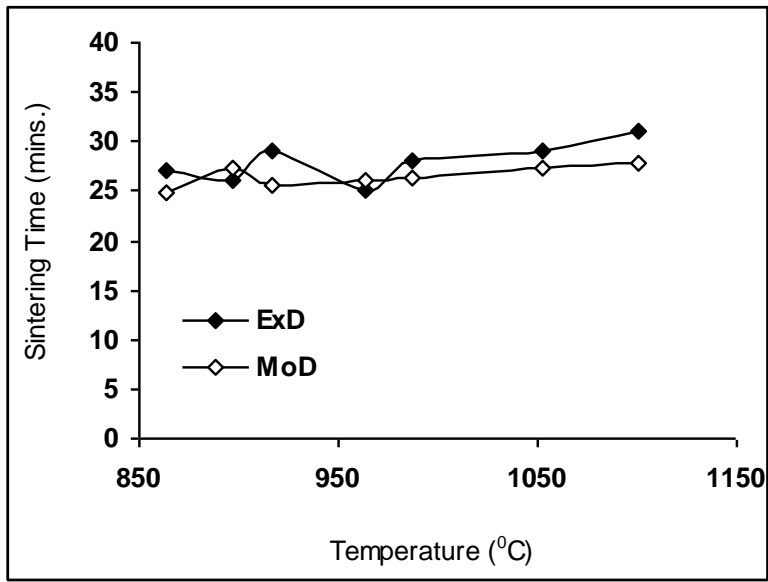

Fig. 7: Comparison of the sintering times (relative to ignition temperature) as obtained from experiment and derived model.

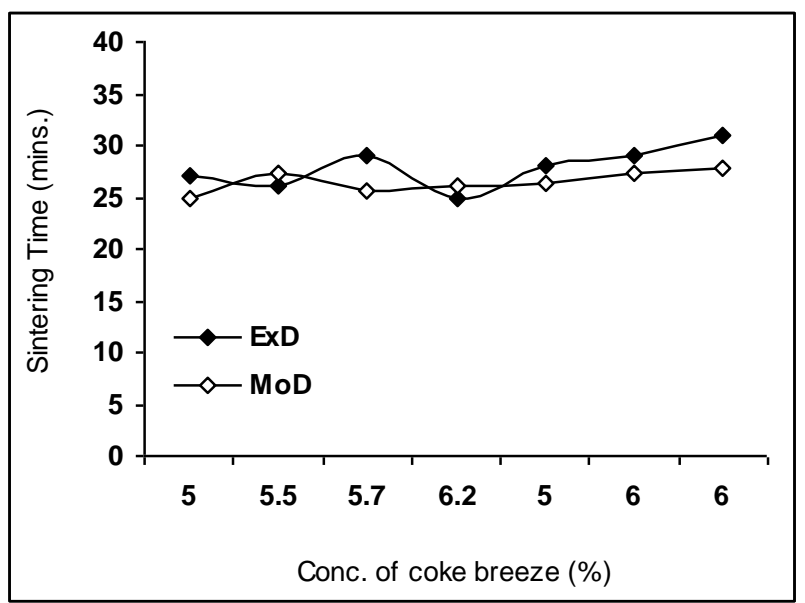

Fig. 8: Comparison of the sintering times (relative to conc. of coke breeze) as obtained from experiment and derived model.

Comparison of derived model with standard model

The validity of the derived model was further verified through application of the Regression Model [7] in predicting the trend of the experimental results for the values of ignition temperatures and coke breeze input concentrations considered. Results predicted by the Regression Model (LSM) were plotted; sintering time against ignition temperature and coke breeze input concentration respectively along with results from the experiment and derived model to analyze its spread and trend relative to results from experiment and derived model.

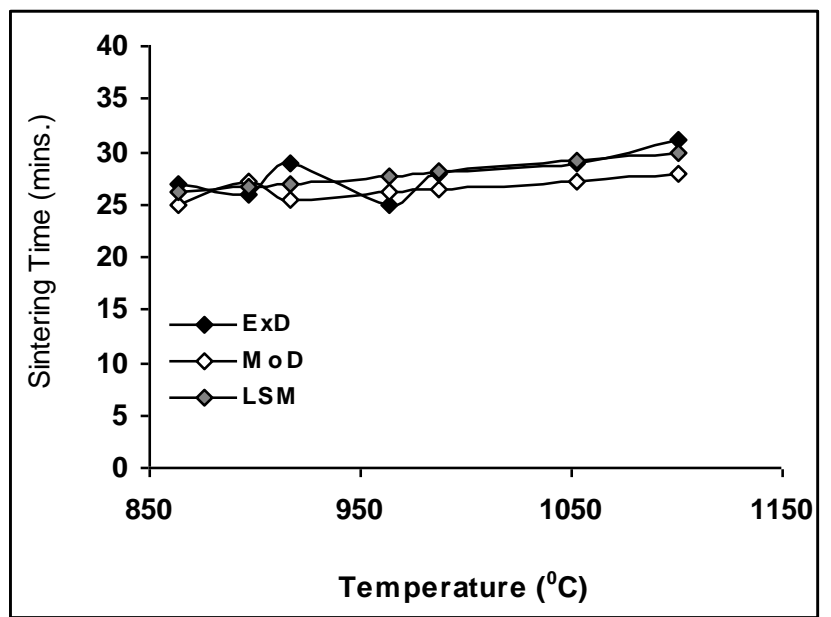

Fig. 9: Comparison of the sintering times (relative to ignition temperature) as obtained from experiment, derived model and regression model 
Comparative analysis of Figs. 9 and 10 shows very close alignment of curves and significantly similar trend of data point's distribution for experimental (ExD), derived model-predicted (MoD) and regression model (LSM) predicted results of sintering time.

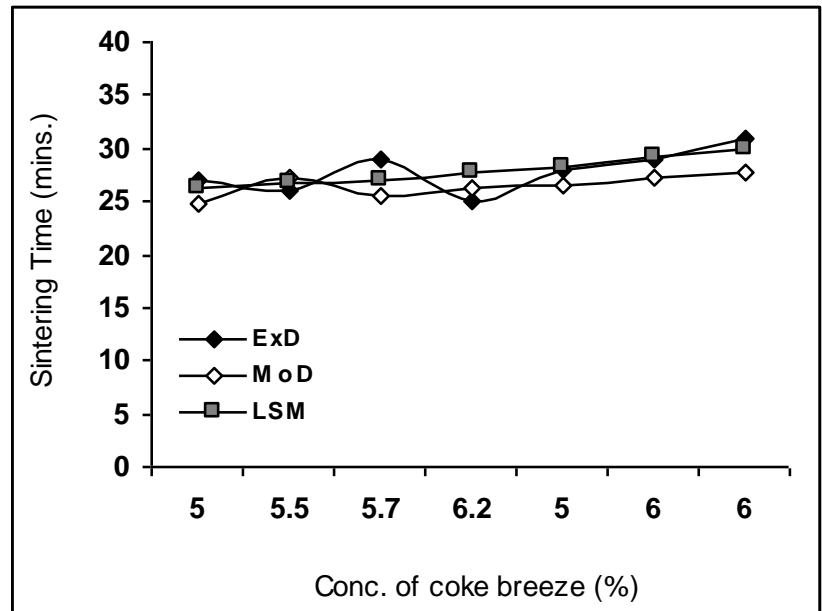

Fig. 10: Comparison of the sintering times (relative to conc. of coke breeze ) as obtained from experiment, derived model and regression model

\subsubsection{Deviational Analysis}

The formulated model was also validated by evaluating the deviation of the model-predicted sintering time from the corresponding experimental values. The recorded deviation is believed to be due to the fact that the surface properties of the ore, and the physiochemical interactions between the ore and the other ingredients believed to have played vital roles (during the process) were not considered during the model formulation. It is expected that introduction of correction factor to the model-predicted sintering time, gives exactly the corresponding experimental values. given by

Deviation (Dv) (\%) of model-predicted sintering time from the corresponding experimental value is

$$
\mathrm{Dv}=\left(\frac{\mathrm{P}_{\mathrm{S}}-\mathrm{E}_{\mathrm{S}}}{\mathrm{E}_{\mathrm{S}}}\right) \times 100
$$

Where

$$
\begin{aligned}
& \mathrm{P}_{\mathrm{S}}=\text { Model-predicted sintering time (mins.) } \\
& \mathrm{E}_{\mathrm{S}}=\text { Sintering time obtained from experiment (mins.) }
\end{aligned}
$$

Since correction factor $(\mathrm{Cv})$ is the negative of the deviation,

$\mathrm{Cv}=-\mathrm{Dv}$

Substituting equation (11) into equation (12) for Dv,

$$
\mathrm{Cv}=-100\left(\frac{\mathrm{P}_{\mathrm{S}}-\mathrm{E}_{\mathrm{S}}}{\mathrm{E}_{\mathrm{S}}}\right)
$$

It was observed that addition of the corresponding values of $\mathrm{Cv}$ from equation (13) to the modelpredicted sintering time gave exactly the corresponding experimental values [5]. 


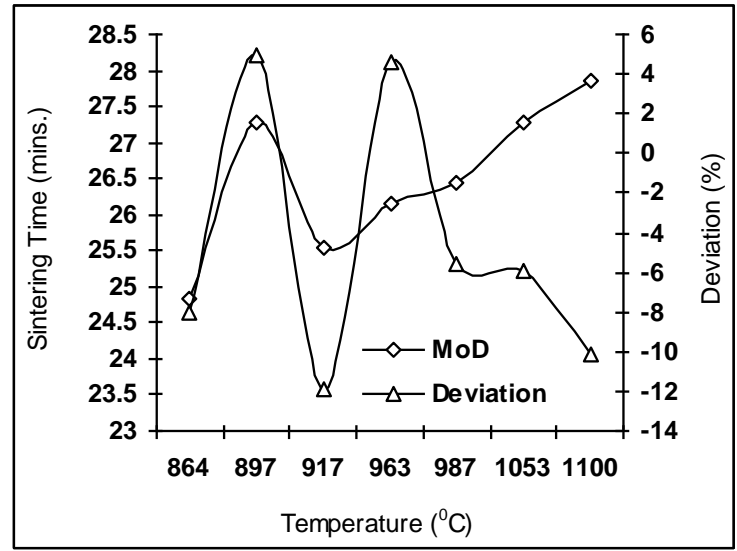

Fig. 11: Variation of model-predicted sintering time (relative to ignition temperature) with its associated deviation from experimental values

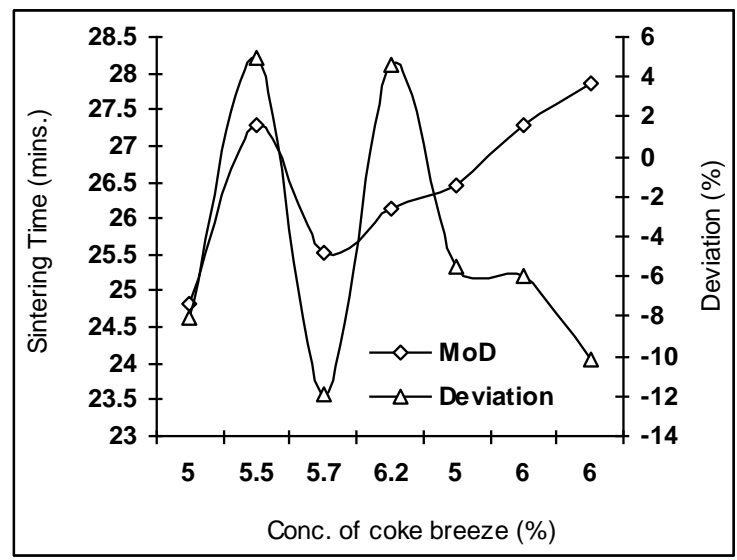

Fig. 12: Variation of model-predicted sintering time (relative to conc. of coke breeze) with its associated deviation from experimental values

Figs. 11 and 12 show that the maximum deviation of the model-predicted sintering time from the corresponding experimental values is less than $11 \%$ and quite within the acceptable deviation limit of experimental results. These figures show that least and highest magnitudes of deviation of the model-predicted sintering time (from the corresponding experimental values) are +4.57 and $-10.17 \%$ which corresponds to sintering times: 26.1424 and 27.8467 mins, ignition temperatures; 963 and $1100^{\circ} \mathrm{C}$ and coke breeze input concentrations: 6.2 and $6.0 \%$ respectively.

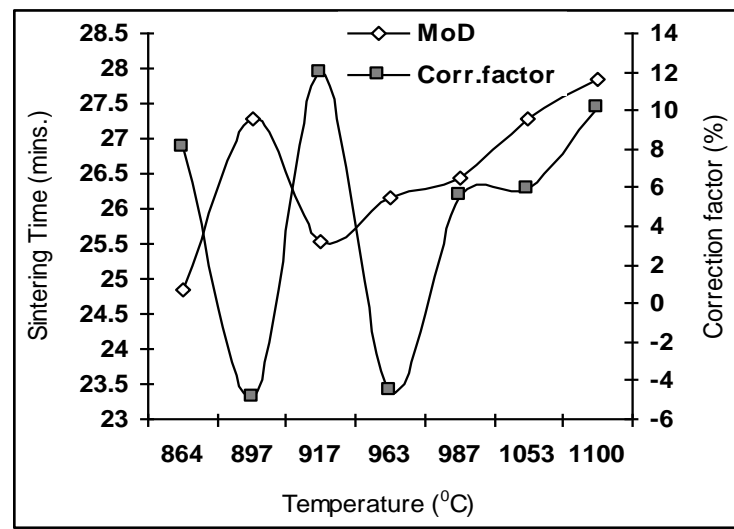

Fig. 13: Variation of model-predicted sintering time (relative to ignition temperature) with its associated correction factor 
Comparative analysis of Figs. 11-14 indicates that the orientation of the curve in Figs. 13 and 14 is opposite that of the deviation of model-predicted sintering time (Figs. 11 and 12). This is because correction factor is the negative of the deviation as shown in equations (12) and (13). It is believed that the correction factor takes care of the effects of the surface properties of the ore, and the physiochemical interactions between the ore and the other ingredients believed to have played vital roles (during the process) were not considered during the model formulation. Figs. 13 and 14 indicate that the least and highest magnitudes of correction factor to the model-predicted sintering times are -4.57 and $+10.17 \%$ which corresponds to sintering times: 26.1424 and 27.8467 mins, ignition temperatures; 963 and $1100^{\circ} \mathrm{C}$ and coke breeze input concentrations: 6.2 and $6.0 \%$ respectively.

It is important to state that the deviation of model predicted results from that of the experiment is just the magnitude of the value. The associated sign preceding the value signifies that the deviation is deficit (negative sign) or surplus (positive sign).

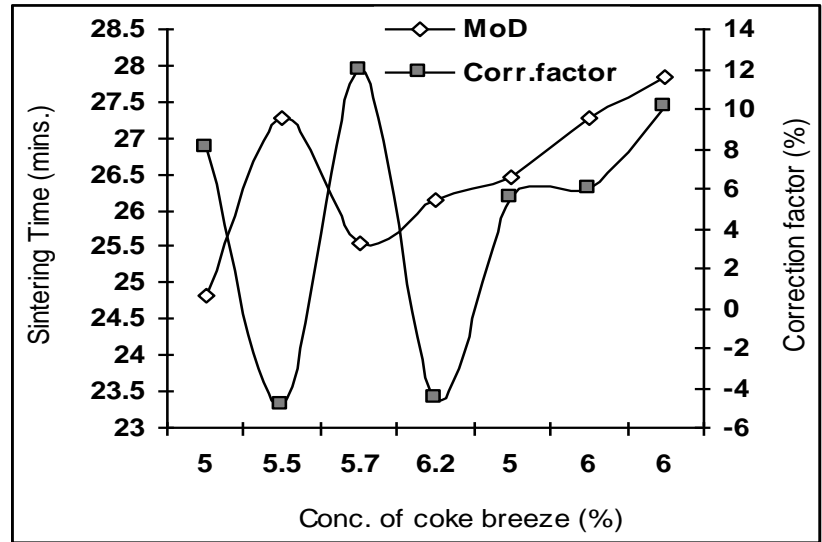

Fig. 14: Variation of model-predicted sintering time (relative to conc. of coke breeze) with its associated correction factor

\section{Conclusion}

Particulate sintering of iron ore has been carried out and empirical analysis of the sintering time based on the coke breeze input concentration and ignition temperature were also successfully obtained through first principle application of a derived model which functioned as a evaluative tool. The derived model; indicates that amongst ignition temperature and coke breeze input, sintering time is more significantly affected by the coke breeze input concentration. This is based on the higher correlation it makes with sintering time compared to applied ignition temperature, all other process parameters being constant. The validity of the model was rooted in the core expression $S-K \alpha \approx(\sqrt{ } T)^{N}$ where both sides of the expression are correspondingly approximately almost equal. Sintering time per unit rise in the operated ignition temperature as obtained from experiment, derived model and regression model were evaluated as $0.0169,0.0128$ and 0.0159 mins. $/{ }^{0} \mathrm{C}$ respectively. Similarly, sintering time per unit coke breeze input concentration as obtained from experiment, derived model and regression model were evaluated as 4.0, 3.0183 and 3.7537 mins./ \% respectively indicating a significant proximate agreement and validity of the model. The standard error (STEYX) incurred in predicting sintering time for each value of the ignition temperature and coke breeze input concentration considered, as obtained from the experiment, derived model and regression model are 1.6646, 0.7678 and $2.98 \times 10^{-5} \%$ as well as 2.2128 , 1.0264 and $1.2379 \%$ respectively. The maximum deviation of mode-predicted results from the corresponding experimental values was less than $11 \%$.

\section{References}

[1] D. F. Ball, J. Dartnell, J. Davison, A. Grieve, R. Wild, Agglomeration of iron ores. Heinemann Educational books. American Elsevier Publishing Company, Inc., USA. 1973.

[2] A. Gross, E. A. Anthony, Particulate Emissions Reduction in Sintering Operation. US Patent No. 564590, August 17, 1976.

[3] N. A. El-Hussiny, M. E. H. Shalabi, Effect of Recycling Blast Furnace Flue Dust as Pellets on the Sintering Performance. Science of Sintering, 42 (2010) 269-281.

[4] F. Cappel, W. Hastik, Sintering Process fro Iron Ore Mixture. U.S. Patent No. 4168154, Application No. 05/884352, September $18,1979$.

[5] V. I. Nwokocha, The Formation and Stabilization of Calcium Silicate In the Structure of Super Fluxed Sinters.Ph. D Thesis, Nnamdi Azikiwe University, Awka, Anambra State, Nigeria, (2011).

[6] C. I. Nwoye, C-NIKBRAN: "Data Analytical Memory" (2008).

[7] Microsoft Excel Version 2003. 